\title{
De seksuele doding dertig jaar later
}

Diagnostische vergelijking tussen twee proefschriften: R.C. Hoekstra, Seksuele doding (1969) en D.J. van Beek, De delictscenarioprocedure bij seksueel agressieve delinquenten (1999).

H.J.C. van Marle*

Wanneer alleen al de titels van beide forensisch psychiatrische proefschriften naast elkaar worden gelegd, valt een groot verschil op. Bij Hoekstra gaat het om een bondig feit, bij Van Beek om een delictscenario, een opbouw van verschillende gebeurtenissen. In de dertig jaar die tussen beide proefschriften ligt blijkt zich op het eerste gezicht een belangrijke verandering te hebben voorgedaan. De seksuele doding als feit heeft zich niet weten te handhaven binnen het forensisch psychiatrisch denken; het bleek waarschijnlijk ingewikkelder dan aanvankelijk gedacht. In de recente literatuur zijn er ook geen geschriften meer met die titel te vinden, terwijl de term 'delictscenario' veelvuldig valt te constateren.

In het hier volgende zal ik eerst beide proefschriften in hun wetenschappelijk discours samenvatten, waarbij kort de indelingen van andere wetenschappers als wetenschappelijke parameters zullen worden vermeld. Beide auteurs hebben immers hun onderzoek uitgevoerd op grond van de indelingen van ernstige seksuele misdrijven zoals die in de recente literatuur van hun tijd zijn te vinden geweest. Een wereld van verschil overigens hetgeen uit het volgende moge blijken.

\section{Seksuele doding}

De psychiater Hoekstra uit de dr. S. van Mesdagkliniek te Groningen heeft zijn proefschrift geschreven op de wijze zoals die verwacht mag worden voor een psychiater destijds werkzaam in de Van Mesdagkliniek. Het is een streng psychoanalytisch gebouw met een sterke psychodynamische diagnos-

* Prof. dr. H.J.C. van Marle, hoogleraar forensische psychiater K.U. Nijmegen en psychiatrisch adviseur Ministerie van Justitie; psychoanalytisch psychotherapeut Dr. H. van der Hoevenkliniek te Utrecht. Oud geneesheer-directeur Dr. S. van Mesdagkliniek te Groningen. Oud geneesheer-directeur Pieter Baan Centrum te Utrecht. 
tiek. Deze diagnostiek is dimensioneel van aard, dit wil zeggen dat bepaalde dimensies van de persoonlijkheid in aard en sterkte worden vastgesteld. Men denke hierbij aan de agressie, de gewetensfunctie of de adaptatievermogens. In deze wordt gebruik gemaakt van het 'diagnostisch profiel' zoals dat destijds door Anna Freud met haar medewerkers is uitgewerkt (1965). Hierbij wordt de psychopathologie geëvalueerd in alle instanties van de persoonlijkheid (Es, Ich, en Über-Ich) in zoverre deze afwijken van de normale ontwikkeling ervan. A. Freud heeft dit profiel in eerste instantie voor de kinderpsychiatrie ontwikkeld maar uiteindelijk is het aangepast aan de volwassene. De maatstaf is dus een relatief stabiel einde waarop de uiteindelijke kinderlijke ontwikkeling is uitgekomen. De rijpheid van de ontwikkeling van de persoonlijkheidsstructuur is hierbij het onderliggend denkkader. Tevens wordt in dit profiel ook een schatting gemaakt van de behandelbaarheid van de geconstateerde tekorten en de verdere positieve mogelijkheden tot genezing. De graad van normaliteit wordt verder in het profiel beoordeeld naar de kwaliteit van functioneren in seksualiteit, werk en andere sublimatoire activiteiten (het gevoel van welbevinden in het dagelijks leven dat ermee gekregen is, en naar de kwaliteit van de object- en sociale relaties, Hoekstra; 1969).

De stap van het diagnosticeren met het 'diagnostisch profiel' naar de diagnostiek van de seksuele doding heeft Hoekstra kunnen maken vanuit de autoriteit van de Groningse psychoanalytische school van prof. dr. W.K. van Dijk. In diens proefschrift 'De psychogene psychose' (1963) werd namelijk beschreven hoe een psychotisch syndroom uiteindelijk kan ontstaan door de inwerking van psychogene factoren, i.c. een psychotrauma.

Deze fases zijn:

1. een premorbide spanningstoestand,

2. het psychotrauma,

3. de intermediaire fase waarin de symptomen onder 1 . worden geïntensiveerd, en uiteindelijk

4. de psychotische fase.

Een analogie wordt gevonden met de katathyme crisis van Wertham (1937). De overeenkomsten tussen het ontstaan van de psychogene psychose en de katathyme crisis hebben ertoe geleid dat Hoekstra de seksuele doding binnen dit kader heeft kunnen plaatsen en via deze methodiek een analyse heeft gemaakt van acht TBS-gestelden die hij in de Van Mesdagkliniek heeft onderzocht. 
Overigens zou een proefschrift als het zijne niet meer mogelijk zijn vanwege de zeer gedetailleerde vermelding van de psychiatrische voorgeschiedenis alsmede van het delict van de onderzochten. Deze zijn vrijwel allemaal door de collegae in de Van Mesdagkliniek herkenbaar geweest, zo niet daar buiten. Destijds lagen de grenzen van de medisch geheimhouding wel anders dan tegenwoordig. Daarom zijn wij op dit moment (2001) nog in het bezit van een achttal boeiende ziektegeschiedenissen, die zeker voor het onderwijs in de forensische psychiatrie van groot belang blijven.

\section{Classificatie van seksuele moorden}

Hoekstra stond niet alleen in zijn pogingen seksuele doders te beschrijven en te vergelijken. Hij haalt andere indelingen aan, namelijk die door Nass (1966), die van Berg (1963) en die van Revitch (1965). Deze drie auteurs hadden de seksuele doding als stafbaar feit centraal gesteld in hun schemata. Ter overpeinzing en als historische noot worden ze hier opgesomd.

Nass:

1. Het vrijwillig geslachtsverkeer en het doden gedurende de geslachtsdaad.

2. Vrijwillig geslachtsverkeer en het doden onmiddellijk aansluitend aan de geslachtsdaad.

3. Afgedwongen geslachtsverkeer en het doden gedurende de geslachtsdaad.

4. Afgedwongen geslachtsverkeer en het doden onmiddellijk na de geslachtsdaad. ( 1 en 3 worden als primaire seksuele doding gekenmerkt en 2 en 4 als secundaire).

Berg:

1. Het zonder overleg doden in het kader van een seksuele handeling.

2. Het met overleg doden uit een ander motief, met behulp van een seksuele handeling.

3. Het doden om een seksuele handeling mogelijk te maken.

4. Het doden achteraf om ontdekking van een seksueel delict te voorkomen.

5. Het sadistisch hoogtepunt van een seksuele handeling.

6. Het doden als seksueel equivalent.

Revitch:

1. De impulsieve moord en bedreiging met geweld.

2. De dwangmatige moord en bedreiging met geweld. 
3. De seksuele moord in een katathyme crisis.

Hoekstra's voorkeur voor A. Freud's diagnostisch profiel komt voort uit zijn behoefte tot psychiatrische en psychoanalytische diagnostiek.

\section{De delictscenarioprocedure}

Inmiddels staan er dertig jaren tussen het eerst genoemde proefschrift en het tweede. Niet alleen is de invloed daarvan te zien aan de boekomslag van beide proefschriften, maar ook aan de gerefereerde literatuur. In het tweede proefschrift is die voornamelijk Angelsaksisch van aard en dan met een specifieke oriëntatie op Noord-Amerikaanse behandelingprogramma's, in tegenstelling tot de Duitse literatuur die uitvoering in het eerste proefschrift wordt geciteerd. Het is ook niet meer het psychoanalytisch of psychodynamisch referentiekader dat de leidraad vormt tot het empirisch onderzoek, maar de cognitief gedragtherapeutische methode, met duidelijke wortels in de leertheorie. Expliciet wordt vermeld dat de primaire doelstelling van de diagnostiek die van het voorkomen van recidive is, en niet meer, zoals bij Hoekstra, inzicht in de persoonlijkheid zelf. De aard van het diagnostiek is dan ook veranderd: niet meer dimensioneel maar categoraal, namelijk in de vorm van typologieën. De leertheorie bevat, zij het bondig, de etiologie zoals die ook aan A. Freud bekend was, namelijk biologische factoren, ervaringen uit de kindertijd, socioculturele context en situationele factoren.

De aanvankelijke typologieën misten een empirische toetsing op betrouwbaarheid en validiteit. Toch blijkt een opvallend consistent beeld naar voren te komen (Van Beek 1999). In zijn algemeenheid is er steeds een viertal typen verkrachters te herkennen. Voor het eerste type zijn de delicten compenserend gedrag, bijvoorbeeld om gevoelens van minderwaardigheid en twijfels over de eigen masculiniteit te verminderen. Seksualiteit neemt daar een centrale plaats in. Een tweede type pleegt zijn delicten voornamelijk uit woede jegens vrouwen. Bij hen staan woede en agressie centraal. Een derde type pleegt zijn delicten op een bizarre en zeer gewelddadige en sadistische wijze. Deze mannen hebben dit geweld nodig om seksueel opgewonden te worden. De fusie tussen seksuele en agressieve verlangens is bij hen essentieel. Tenslotte is in de meeste typologieën een crimineel type verkrachter te onderscheiden, die binnen een algehele criminele levensstijl ook seksuele delicten pleegt. Een antisociale persoonlijkheidsstoornis staat bij deze mannen voorop. 
Knight and Prentky (1990) ontwikkelden echter vanaf het eind van de jaren zeventig een empirisch gebaseerd classificatiesysteem voor verkrachters. Het gaat hier om de opportunistische, de globaal boze, de seksuele en de wraakzuchtige verkrachter, waarbij elk type weer onderverdeeld kan worden in een hoge en een lage sociale competentie. Het seksuele type valt verder te verdelen in een sadistisch en niet sadistisch subtype. Door de complexiteit van het systeem heeft het echter in de klinische praktijk nog bestrekkelijk weinig furore gemaakt, hoewel in academische kringen de erkenning duidelijk toeneemt. Er zijn echter andere indelingen van andere auteurs, zoals Barbaree and Marshall (1991), Hall and Hirschman (1991). Het eerste model berust sterk op de polariteit tussen remming en ontremming, de laatste op motivationele factoren. Deze zijn fysiologisch seksuele opwinding, cognities die seksueel geweld rechtvaardigen, affectieve discontrole en specifieke ontwikkelingsfactoren (bijvoorbeeld als gevolg van fysiek of seksueel misbruik). Tot slot dient nog het confluentiemodel van Malamuth (1991) genoemd te worden die de onderlinge interacties en versterking van verschillende risicofactoren in beeld heeft gebracht in een seksueel promiscuïteitpad en een vijandig masculiniteitpad.

Vervolgens doet Van Beek onderzoek op grond van zijn klinische ervaring met TBS-gestelden in de Van der Hoevekliniek naar de drie delictscenarioprofielen, nl: het seksualiserende type, het antisociale type en het wraakzuchtige type.

Dit leidt tot een aanzet tot validering van de delictscenarioprofielen en de verantwoording van veranderingen bij de plegers na de delictscenarioprocedure. Het blijkt uiteindelijk dat seksualiserende plegers beter reageren op de delictscenario en terugvalpreventiebehandeling dan de antisociale plegers.

\section{Beschouwing}

Inmiddels is de discussie tussen dimensionele en categorale diagnostiek nog beslist niet gestreden. Het belangrijkste psychiatrisch diagnostisch instrument is momenteel de Diagnostic and Statistic Manual-IV, waartegen het nodige valt in te brengen (o.m. Van Praag 2000). De categorale indeling is te absoluut en geeft door de flexibiliteit van de psychopathologie nogal eens keuzemoeilijkheden. Ook is er nu sprake van 'co-morbiditeit' waardoor iemand opeens twee of meer psychiatrische ziektes kan hebben. Onderscheid tussen primaire, oorzakelijke factoren en secundaire, fenotypische ver- 
schijnselen wordt in dit diagnostisch systeem niet gemaakt. Een belangrijk symptoom zoals depressiviteit komt in meerdere diagnoses voor, terwijl er wellicht één ontstaansgrond aanwezig is.

Vanuit het dimensionele diagnostisch model daarentegen worden persoonlijkheidstrekken in hun intensiteit en aard gemeten. Zo kan er een onderscheid worden gemaakt in mate van impulsiviteit van iemand, tussen introversie en extraversie, angsttolerantie etc. In feite is dit de klassieke vorm van psychologische testdiagnostiek alsmede ook die van de psychoanalyse. De ontwikkeling van deze instrumenten heeft echter geleerd hoe moeilijk die is, met name waar het gaat om overeenstemming te bereiken tussen verschillende onderzoekers en diagnostici. Er zijn momenteel vele modellen in omloop.

Een ander verschil in beide proefschriften is natuurlijk ook het referentiekader, dat van de psychoanalyse bij Hoekstra en dat van de cognitieve gedragstherapie bij Van Beek. Zoals gezegd is het laatste veel pragmatischer van opzet. Bovendien is inmiddels uit de literatuur gebleken dat de klassieke psychoanalytische, psychodynamische psychotherapie bij seksuele delinquenten niet leidt tot een vermindering van de recidive. In hoeverre dit wordt veroorzaakt door een tevens aanwezige persoonlijkheidsstoornis, is nog niet nagegaan. Wel blijkt uit het onderzoek van Van Beek dat de seksualiserende plegers van verkrachtingen een veel betere therapieresponsiviteit hebben dan de anderen. Met name de antisociale persoonlijkheidsgestoorden, danwel zij die antisociaal gerubriceerd worden, hebben een veel slechtere prognose, sterker nog, velen van hen verkillen in hun behandeling en volharden in hun misbruik.

In feite komt het erop neer dat Hoekstra duidelijk inzicht weet te bieden in de totstandkoming van zo'n ernstig delict als seksuele doding en daarbij een duidelijk beeld geeft van het krachtenspel binnen de persoonlijkheid van de dader. Hij doet daarbij recht aan de veelzijdigheid en integriteit van de verschillende persoonlijkheden. Van Beek daarentegen maakt gebruik van de moderne behandelingstechnieken en kiest een empirisch en statistisch gevalideerd model, zoals dat heden ten dage gebruikelijk is. Als zodanig is deze werkwijze de moderne manier van diagnosticeren ten behoeve van een van tevoren vastgestelde vorm van behandelen, die in feite in plaats is gekomen van de vroegere dynamische psychotherapie. Het uitblijven van succes van het paradigma van de laatste is de belangrijkste reden daartoe geweest. Verdere ontwikkelingen van de psychodynamische methode in de richting van 
de cognitieve hebben overigens ook bijgedragen aan het hedendaagse belang van de cognitieve therapieën.

Opvallend is dat waar Hoekstra nog duidelijk de 'doding' als centrale thema behandelt, zo'n eindresultaat bij Van Beek geen rol meer speelt. De seksuele doding is in de loop van de dertig jaar zijn rol kwijt als typisch symptoom van een voorgaande ontwikkeling, zoals de katathyme crisis dat naar voren brengt. Het is niet vruchtbaar gebleken de seksuele doding als een specifiek symptoom van een specifieke psychiatrische aandoening te bekijken, het inzicht dat ook de psychosomatische ziekten hebben moeten volgen. Hoewel Hoekstra vanuit zijn psychodynamiek elk individu uniek maakt in die uiteindelijke daad, en er dus vele wegen naar Rome bleken te leiden, is statistische simplificatie tot drie of vier modellen echter noodzakelijk gebleken om na jaren te kunnen constateren dat er qua behandeling, met name via de delictscenarioprocedure, voortgang kon worden geboekt bij sommige types.

De klinische realiteit heeft in deze ook tot bescheidenheid opgeroepen. De seksuele doding als een noodzakelijk gevolg van een combinatie van persoonlijkheidsfactoren en situatieve factoren is in de praktijk moeilijk te onderzoeken. Niet alleen moeten we afgaan op het relaas van de dader zelf, maar ook blijkt hoezeer de realiteit indringt in de totstandkoming van zo'n daad. Wanneer men namelijk zedendelicten goed onderzoekt blijkt hoe vaak aanrandingen in feite mislukte verkrachtingen zijn en moord en doodslag tamelijk uitwisselbaar zijn bij forensisch psychiatrische analyse. Het vóórkomen ervan (de 'base rate') is gering ten opzichte van ander (seksueel) geweld, zodat vergelijken niet goed mogelijk is. Ook laat de realiteit zien hoe het gebruik van geweld, leidende tot een doding, zeer divers kan zijn. Een indeling in vormen van geweld, de aanleiding daartoe en de persoon van de dader zou ook eens geprobeerd moeten worden. In deze blijkt de classificatie van de seksuele dodingen, hoe verschillend en genuanceerd ook, geen praktische en heeft derhalve geen navolging gevonden.

\section{Conclusie}

Het valt op hoezeer de behandeling van daders van seksuele misdrijven is veranderd op geleide van de toegenomen mogelijkheden van diagnostiek en nosologie. Wetenschappelijke ontwikkelingen in de vorm van statistische bewerkingen, gerandomiseerde controlegroepen etc, hebben hier duidelijk een positieve rol gespeeld. Aan de andere kant mag niet vergeten worden dat 
Hoekstra en Van Beek slechts een klein gedeelte van de seksuele delinquenten hebben onderzocht; maar vier procent van alle veroordelingen voor seksuele misdrijven in Nederland per jaar komt in een TBS-kliniek (Frenken 1999). Op poliklinieken en dagziekenhuizen wordt ook veel gewerkt met de terugvalpreventiebehandeling op grond van een delictscenario en met positief resultaat. Is dit nu voortschrijdende wetenschap?

$\mathrm{Ja}$, mijns inziens is er sprake van een verbetering van onze behandelmethodieken. Deze zijn duidelijker omschreven zodat velen die kunnen uitvoeren, beter te evalueren, en succesvoller. Daarbij mag echter niet vergeten worden dat er in de nieuwe methodieken de techniek en het uiterlijk geraamte centraal staan. De houding van de behandelaars ten opzichte van de behandelden is niet meer expliciet onderwerp van studie. Ook zijn in veel gevallen de insluitings- en uitsluitingscriteria van de groep te behandelen patiënten niet duidelijk, zodat er een selectie optreedt die voor de waarnemer niet meteen zichtbaar is. Het verband tussen diagnose en techniek is bijna komen te vervallen: de daad geeft aanleiding tot de therapie, die blijkbaar voor iedereen goed is. Maar is het wel of geen succes hebben te voorspellen? Wie zijn de uitvallers? Hierbij valt te denken aan de uitkomsten van de klassieke psychiatrische diagnostiek waarbij patiënten met een psychose, met een stoornis in de impulsiviteit of met een gebrekkig geweten, niet in aanmerking komen voor een psychotherapeutische behandeling.

Het bestuderen van de attitude van therapeut tot patiënt, de verdraaiingen die in de relatie tussen beiden kunnen optreden in de vorm van overdracht, het afbakenen van grenzen tussen beiden om vervloeiing te voorkomen, zijn allemaal fenomenen die wij uit de klassieke psychoanalytische benadering hebben verkregen en blijvend hebben verworven. Het is opmerkelijk dat daar momenteel nog zo weinig bij wordt stil gestaan. Op dit moment is er duidelijk sprake van een tweedeling in onze referentiekaders met betrekking tot de aanpak en behandeling van seksuele daders in de TBS: enerzijds wordt er in de interacties een duidelijk beroep gedaan op de psychodynamisch referentiekaders met haar dynamiek en terminologie, anderzijds wordt in de behandeling het vaststaande schema van de delictscenarioprocedure uitgevoerd. Tenzij valt te constateren dat het laatste in het verlengde van het eerste gebeurt, valt dit niet te rijmen en is verdere ontwikkeling van de huidige staat van theorievorming over veranderingsprocessen bij zedendelinquenten noodzakelijk. Er is immers te weinig bekend van de oorzaken, de preventie (wanneer ontwikkeld iemand zich tot een pleger?) en de specificatie van de behandeling. Valt de patiënt uiteindelijk alleen nog te 'sturen' 
door zijn gedachten te beïnvloeden en wordt de rest van de persoon als 'onbehandelbaar' ter zijde gelegd?

\section{Referenties:}

- Beek, D.J. van (1999) De delictscenarioprocedure bij seksueel agressieve delinquenten. Diss. Universiteit van Amsterdam, Gouda Quint, Deventer.

- Hoekstra, R.C. (1969) Seksuele doding: theoretische overwegingen en een empirische explotatie. Diss. Groningen, Deventer. Aanwezig te: Centrale bibliotheek en documentatie Ministerie van Justitie 1031 X d4.

- Wertham, F. (1937) The Catathymic Crisis. Archives of Neurology and Psychiatry, vol. XXXVII, 974. 